02,13

\title{
Новый подход к формированию топологии планарных структур на основе высокотемпературного сверхпроводника YBCO
}

\author{
(ㄱ Д.В. Мастеров, С.А. Павлов, А.Е. Парафин ॠ \\ Институт оризики микроструктур РАН, \\ Нижний Новгород, Россия \\ ๑ E-mail: parafin@ipmras.ru
}

\begin{abstract}
Представлена новая технология формирования планарных сверхпроводниковых структур на основе пленок YВСО с металлическими контактами, полностью исключающая процессы травления. Нужная топология сверхпроводящих элементов из пленки YВСО создается предложенным методом „задающей маски“. Омические контакты к сверхпроводящей структуре изготавливаются методом взрывной фотолитографии. Для исследования возможностей данной технологии были проведены измерения сверхпроводящих мостиков шириной 3,10 и $50 \mu \mathrm{m}$ и тестовых структур для измерения контактного сопротивления.
\end{abstract}

Работа выполнена при поддержке Российского научного фонда (проект 16-19-10478). В работе использовано оборудование ЦКП „Физика и технология микро- и наноструктур“.

DOI: 10.21883/FTT.2017.11.45046.05k

\section{1. Введение}

При традиционном подходе к изготовлению планарных структур на основе пленок высокотемпературного сверхпроводника $\mathrm{YB}_{2} \mathrm{Cu}_{3} \mathrm{O}_{7-x}$ (YВСО) последовательность основных операций следующая. На подложку напыляется YВСО пленка, затем, для дальнейшего формирования омических контактов [1-3], на нее in situ или в другой установке, сразу после напыления YВСО, осаждается металлическая пленка. После напыления этих слоев формируется требуемая топология структуры, для чего используется ионное или химическое травление [3-5]. Для получения изолирующих областей, разделяющих сверхпроводящие элементы, может применяться также ионная имплантация [4,6,7]. Формирование топологии является критически важным этапом при изготовлении планарных структур на основе ҮВСО пленок, существенно влияющим на конечные параметры прибора, что обусловлено высокой чувствительностью свойств ҮВСО пленок к внешним воздействиям.

При химическом травлении ҮВСО возникает значительный и плохо контролируемый уход размеров формируемой структуры относительно фоторезистивной маски („подтрав“), связанный с наличием медленно (по сравнению с ҮВСО) растворимых в травителе вторичных фаз. Кроме того, во время травления край пленки YВСО повреждается на бо́льшую, порядка $1 \mu \mathrm{m}$, глубину [5]. Сложности, возникающие при ионном травлении YВСО, связаны, прежде всего, с низкой скоростью травления материала пленки, что требует повышения стойкости защитной маски. Кроме того, образец во время травления нагревается и его необходимо охлаждать, чтобы не произошла деградация ҮВСО пленки. Следует отметить, что поскольку коэффициент диффузии кислорода в пленке YВСО в направлении $a-b$ во много раз больше, чем в направлении оси $c$, то структуры, полученные травлением, и, следовательно, с открытыми в направлении $a-b$ слоя- ми ҮВСО, более подвержены деградации. При создании изолирующих областей методом ионной имплантации возникают сложности с удалением фоторезистивной маски, что связано с задубливанием фоторезиста при воздействии высокоэнергетичных ионов.

При химическом травлении металлических слоев к повреждениям поверхности и края ҮВСО из-за контакта с травителем добавляется также значительный и плохо контролируемый подтрав под фоторезистивную маску, что связано с низкой адгезией металла к пленке. Удаление металла с поверхности ҮВСО ионным травлением может приводить к деградации свойств структуры из-за радиационного воздействия ионов на пленку. Травление металла может оказывать повышенное негативное влияние в случаях, когда металлический слой удаляется с YВCO пленок толщиной несколько десятков нанометров, например, при изготовлении болометров, а также в случае структур содержащих слабые связи - джозефсоновские контакты. Для формирования контактов к YВСО пленкам могут быть использованы только благородные металлы. Применение других металлов приводит к тому, что металл взаимодействует с ҮВСО, „вытягивая“ из пленки кислород. В результате сверхпроводник под слоем металла деградирует, контакт становится нелинейным и имеет большое сопротивление. Обычно для контактов к YВСО используется золото, которое не взаимодействует с пленкой химически и не диффундирует в нее [3]. Серебро так же не взаимодействует химически с YВСО, и, в отличие от золота, может диффундировать в пленку.

С целью получения высоких характеристик получаемых структур за счет минимизации негативных воздействий на пленку YВСО в настоящей работе исследовалась возможность формирования топологии сверхпроводящих элементов и контактов к ним без использования операций травления или ионной имплантации. 
Исследования проводились на пленках, выращенных на подложках из сапфира. Топология сверхпроводниковых структур формировалась предложенным нами методом „задающей маски“ [8]. Низкоомные омические контакты со сложным рисунком и размерами в единицы $\mu \mathrm{m}$ формировались методом взрывной фотолитографии. В настоящей работе в качестве материала для изготовления контактов использовалось серебро.

\section{2. Технология изготовления и характеристики структур}

В настоящей работе последовательность формирования топологии сверхпроводниковых структур предложенным методом задающей маски была следующей:

1. На сапфировой $\left(\mathrm{Al}_{2} \mathrm{O}_{3}\right)$ подложке (использовался $r$-срез) формируется маска из фоторезиста, после чего при комнатной температуре на подложку напыляется слой аморфного оксида церия $\left(\right.$ cold $\left.\mathrm{CeO}_{2}\right)$.

2. Фоторезист вместе с напыленной на него пленкой cold $\mathrm{CeO}_{2}$ удаляется с подложки в ацетоне в ультразвуковой ванне. Таким образом, на подложке образуется „задающая маска“ из аморфной пленки оксида церия, в которой вскрыты окна для последующего формирования в них сверхпроводящих элементов.

3. На подложку осаждается оксид церия при температуре $T_{d}=900^{\circ} \mathrm{C}$. В результате в окнах маски формируется подслой эпитаксиального оксида церия $\left(\right.$ epiCeO $\left.\mathrm{O}_{2}\right)$, а в областях, где на подложке осталась пленка coldCeO 2 нетекстурированный поликристалл $\mathrm{CeO}_{2}$. Для создания задающей маски использовался слой coldCeO 2 толщиной $100 \mathrm{~nm}$. Толщина подслоя еріСеО 2 в окнах маски составляла $50 \mathrm{~nm}$.

4. В завершении на подложку магнетронным распылением осаждается ҮВСО при температуре $T_{d}=800^{\circ} \mathrm{C}$. В результате, в окнах маски, на сформированной подложке $\mathrm{Al}_{2} \mathrm{O}_{3}-$ epiCeO $\mathrm{O}_{2}$, получаются сверхпроводящие элементы заданного рисунка, а между ними - изолирующие области.

Оксид церия наносился распылением керамической мишени состава $\mathrm{CeO}_{2}$ излучением эксимерного лазера LPX $200(\lambda=248 \mathrm{~nm})$ в атмосфере кислорода при давлении $P=20 \mathrm{~Pa}$. Пленки YВСО осаждались методом магнетронного напыления в стандартных условиях для эпитаксиального роста ҮВСО [9] при температуре подложки $T_{d}=800-850^{\circ} \mathrm{C}$ и давлении газовой смеси $\operatorname{Ar}(50 \%) / \mathrm{O}_{2} \quad P=75 \mathrm{~Pa}$. Более подробно этот этап создания сверхпроводящей структуры методом задающей маски рассмотрен в работе [8]. В работе [10] таким методом были изготовлены мостики с джозефсоновскими контактами длиной $6,50,100$ и $150 \mu \mathrm{m}$.

Для завершения изготовления сверхпроводящей структуры необходимо сформировать металлические омические контакты с низким контактным сопротивлением. В наших работах $[8,10]$ омические контакты к мостикам формировались термическим напылением серебра через маску сразу после напыления пленки YВСО. Возможность напыления контактов через маску на реальные структуры сильно ограничена, так как требуемые размеры контактов малы. В связи с этим, в настоящей работе рассмотрена возможность формирования низкоомных омических контактов со сложным рисунком и размерами в единицы $\mu$ т методом взрывной фотолитографии.

Как известно, при взрывной фотолитографии после нанесения на подложку фоторезиста и формирования в его слое нужного рисунка, подложка запыляется металлом, затем фоторезист удаляется и уносит слой металла, находящийся на его поверхности. Металл, осажденный в окна фоторезистивной маски, остается на поверхности пленки YВСО. Нанесение фоторезиста на пленку и его последующее удаление в ацетоне не оказывают заметного воздействия на характеристики пленки. Контактное сопротивление сразу после проведения взрывной фотолитографии очень велико, так как в окнах под контакты YВСО пленка подвергается воздействию проявителя, и, кроме того возможно загрязнение поверхности пленки остатками фоторезиста. Нами был определен режим вжигания контактов, позволяющий получить низкое контактное сопротивление, а также обеспечить сплошную структуру пленки серебра и ее хорошую адгезию к пленке YВСО при сохранении высоких параметров пленки. Вжигание контактов проводилось при температуре $T=500^{\circ} \mathrm{C}$ в атмосфере кислорода в течение пяти минут. Такой отжиг не ухудшает параметров ҮВСО пленки, и более того, часто такой режим отжига используется на завершающей стадии роста YВСО пленки для насыщения ее кислородом.

По описанному выше технологическому процессу был изготовлен образец, включающий в себя сверхпроводящие болометры терагерцового диапазона, интегрированные со спиральной металлизированной антенной, тестовую структуру для измерения контактного сопротивления и сверхпроводящие мостики шириной 3,10 и $50 \mu \mathrm{m}$ для определения параметров сверхпроводящих элементов. Толщина ҮВСО составляла $80 \mathrm{~nm}$, толщина пленки серебра - $200 \mathrm{~nm}$.

На рис. 1 приведена фотография центральной части сверхпроводящего болометра терагерцового диапазона, интегрированного со спиральной металлизированной антенной. Показаны три области, формирующие структуру болометра, изготовленного методом задающей маски. Область I - активный элемент болометра, представляющий собой мостик из сверхпроводящей пленки YВСО, его ширина $3 \mu \mathrm{m}$, длина $6 \mu \mathrm{m}$. Область II - спиральная антенна (она же выполняет функцию омического контакта). В этой области сверхпроводящая пленка YВСО покрыта пленкой серебра. Минимальная ширина полоски антенны - $6 \mu \mathrm{m}$. Видно, что пленка серебра сплошная. Область III - изолирующая область. Неровность края рисунка ҮВСО и серебра составляет менее $0.25 \mu \mathrm{m}$.

На рис. 2 показан элемент тестовой структуры для измерения контактного сопротивления четырехзондовым 


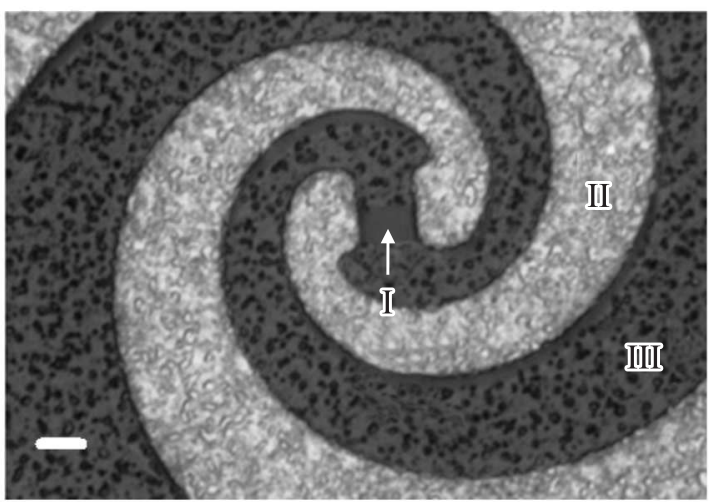

Рис. 1. Фотография центральной части структуры сверхпроводящего болометра терагерцового диапазона, интегрированного со спиральной металлизированной антенной. Метка $-5 \mu \mathrm{m}$.

методом. Токовые контакты на рис. 2 обозначены как „І“, потенциальные - как „U“. Тестовая структура содержит три элемента с различной площадью контактной области металл-сверхпроводник. Длина контактов $L$ вдоль протекания тока: 50, 20 и $10 \mu \mathrm{m}$. Ширина всех контактов $w=50 \mu \mathrm{m}$.

Вольт-амперные характеристики тестовой структуры для измерения контактного сопротивления линейны, и их наклон определяет величину контактного сопротивления. Полученные значения контактных сопротивлений для трех элементов структуры с различной длиной контакта $L$ приведены в таблице. Из таблицы видно, что измеренное сопротивление контакта $R_{c}$ обратно пропорционально его площади.

Плотность критического тока, измеренная на мостиках шириной 3,10 и $50 \mu \mathrm{m}$, независимо от ширины мостика составила $J_{c}=4.0 \cdot 10^{6} \mathrm{~A} / \mathrm{cm}^{2}$ при температуре $T=77 \mathrm{~K}$, что свидетельствует о том, что край мостиков не поврежден. Критическая температура $T_{c}$ была равна $88 \mathrm{~K}$.

\section{3. Результаты и обсуждение}

Рассмотрим эквивалентную схему исследуемого контакта YВСО-серебро, приведенного на рис. 2. В предположении, что плотность тока в сверхпроводнике и

Полученные значения контактных сопротивлений для изготовленных структур различной длины $L$

\begin{tabular}{c|c|c}
\hline $\begin{array}{c}\text { Размер контак- } \\
\text { тной площадки } \\
w \times L, \mu \mathrm{m}\end{array}$ & $\begin{array}{c}\text { Измеренное сопро- } \\
\text { тивление контакта } \\
R_{C}, \mathrm{~m} \Omega\end{array}$ & $\begin{array}{c}\text { Удельное контактное } \\
\text { сопротивление } \\
r_{c}, \Omega \cdot \mathrm{cm}^{2}\end{array}$ \\
\hline $50 \times 50$ & 0.87 & $2.17 \cdot 10^{-8}$ \\
$50 \times 20$ & 1.96 & $1.96 \cdot 10^{-8}$ \\
$50 \times 10$ & 3.91 & $1.96 \cdot 10^{-8}$
\end{tabular}

металле поперек протекания электрического тока однородна, эквивалентную схему контакта можно представить в виде, показанном на рис. 3. Эквивалентная схема описывает контакт сверхпроводник-металл как распределенную структуру, в которой происходит перетекание тока из сверхпроводящего электрода контакта в металлический электрод. Здесь $r_{\square}-$ сопротивление пленки металла на квадрат, $r_{c}-$ удельное контактное сопротивление между металлом и сверхпроводником, $w$ - ширина контакта, $L-$ длина контакта. $U(x)$ и $I(x)$ - распределение вдоль металлического электрода контакта (по оси , $x^{\text {“ }}$ на эквивалентной схеме) напряжения и силы тока в контакте. Элементы, показанные на эквивалентной схеме, представляют собой: $r_{\square} d x / w-$ сопротивление пленки металла шириной $w$ и длиной $d x, r_{c} /(w d x)$ - контактное сопротивление сверхпроводник-металл через площадь $w \times d x$.

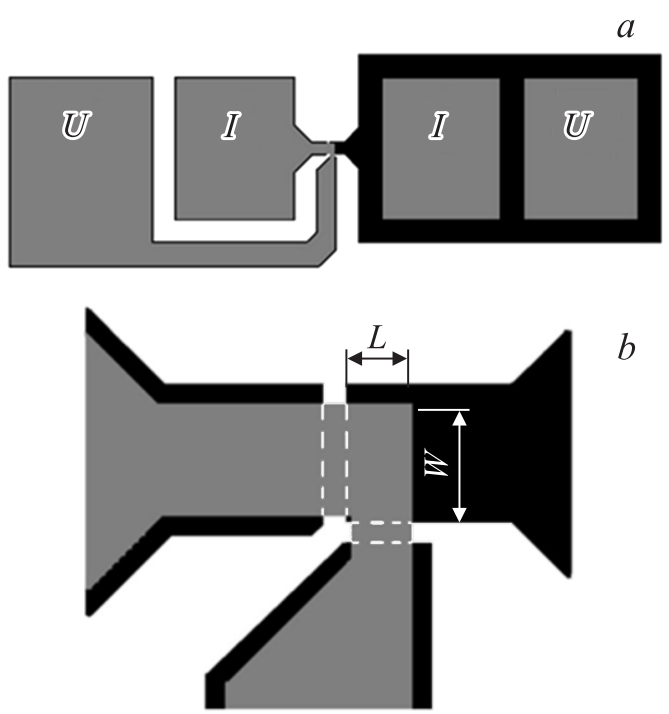

Pис. 2. Элемент тестовой структуры для определения величины контактного сопротивления серебро - ҮВСО. (a) общий вид тестового элемента. Структура включает в себя область исследуемого омического контакта (расположена в центре) и четыре контактные площадки. Черное поле на рисунке - пленка ҮВСО, серое - серебро. $(b)$ - область исследуемого омического контакта (увеличена). $L$ и $w-$ размеры области контакта серебро - YВСО. Белый пунктир показывает границы пленки ҮВСО.

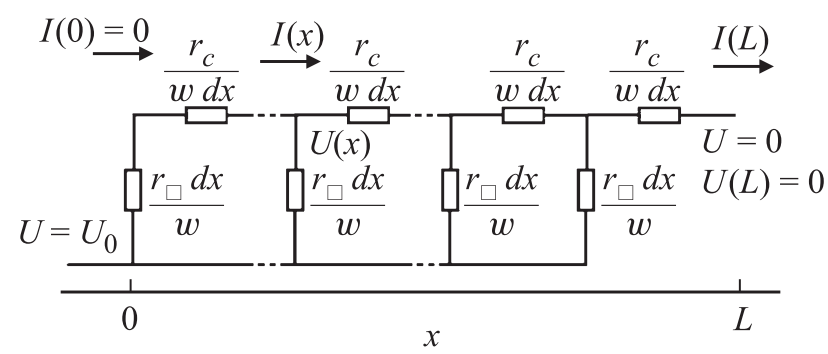

Рис. 3. Эквивалентная схема контакта сверхпроводникметалл. 
С учетом того, что $I(0)=0$ (ток в металлическом электроде при $x=0$ равен нулю) и $U(L)=0$ (напряжение при $x=L$ равно нулю) распределение $U(x)$ и $I(x)$ вдоль металлического электрода контакта по оси , $x^{\text {“ }}$ выражается следующими формулами:

$$
\begin{gathered}
U(x)=U_{0}\left(1-\frac{\operatorname{ch} \frac{x}{\lambda}}{\operatorname{ch} \frac{L}{\lambda}}\right), \\
I(x)=\frac{U_{0}}{r_{\square}} \frac{w}{\lambda} \frac{\operatorname{sh} \frac{x}{\lambda}}{\operatorname{ch} \frac{L}{\lambda}}
\end{gathered}
$$

где $\lambda=\sqrt{r_{c} / r_{\square}}-$ характерная длина растекания тока в контакте. Полный ток через контакт равен

$$
I_{0}=\frac{U_{0}}{r_{\square}} \frac{w}{\lambda} \text { th } \frac{L}{\lambda} .
$$

Следовательно, измеряемое сопротивление контакта $R_{C}$, которое есть отношение измеряемого напряжения на контакте к полному току, равно

$$
R_{C}=r_{\square} \frac{\lambda}{w} \operatorname{cth} \frac{L}{\lambda} .
$$

Распределение тока в контакте определяется соотношением длины контакта $L$ и длины растекания $\lambda$. В случае длинного контакта, когда $L>\lambda$, распределение тока неоднородно. При коротких, по сравнению с $\lambda$, длинах контакта $L$ выражение (4) переходит в

$$
R_{C}=\frac{r_{c}}{w L}
$$

Отсюда, зная площадь контакта $w L$, можно вычислить величину удельного контактного сопротивления между металлом и сверхпроводником

$$
r_{c}=R_{C} \times w L .
$$

В этом случае величина измеряемого контактного сопротивления $R_{C}$ будет обратно пропорциональна площади контакта, что и демонстрируют результаты, приведенные в таблице. Величина удельного контактного сопротивления равна $2 \cdot 10^{-8} \Omega \cdot \mathrm{cm}^{2}$. Это величина соответствует лучшим значениям контактного сопротивления, получаемым при напылении металла на пленку YВСО in situ [2].

\section{4. Заключение}

Проведенные исследования показали, что взрывная фотолитография в сочетании с отжигом структур дает возможность получать металлические контакты к пленке ҮВСО размерами в единицы $\mu \mathrm{m}$ и низким удельным контактным сопротивлением: $2 \cdot 10^{-8} \Omega \cdot \mathrm{cm}^{2}$. Такие результаты, совместно с применением метода задающей маски, позволяют говорить о создании новой технологии формирования планарных ҮВСО структур с параметрами, соответствующими современному передовому уровню, без использования процессов травления.

\section{Список литературы}

[1] Q.Y. Ma, M.T. Schmidt, E.S. Yang, Siu-Wai Chan, D. Bhattachayra, J.P. Zheng, H.S. Kwok. J. Appl. Phys. 71, 4082, (1992).

[2] J.W. Ekin, S.E. Russek, C.C. Clickner, B. Jeanneret. Appl. Phys. Lett. 62, 369, (1993).

[3] Ф.В. Комиссинский, Г.А. Овсянников, З.Г. Иванов. ФТТ 43, 769, (2001).

[4] M. Malnou, C. Feuillet-Palma, C. Ulysse, G. Faini, P. Febvre, M. Sirena, L. Olanier, J. Lesueur, N. Bergeal. J. Appl. Phys. 116, 074505 (2014).

[5] E.A. Vopilkin, N.V. Vostokov, A.E. Parafin. Phys. Low-Dim. Struct. 5/7, 177 (2002).

[6] G.J. Clark, F.K. LeGoues, A.D. Marwick, R.S. Laibowitz, R. Koch. Appl. Phys. Lett. 51, 1462 (1987).

[7] В.К. Васильев, Д.С. Королев, С.А. Королев, Д.В. Мастеров, А.Н. Михайлов, А.И. Охапкин, С.А. Павлов, А.Е. Парафин, П.А. Юнин, Е.В. Скороходов, Д.И. Тетельбаум. Поверхность 4, 80 (2016).

[8] Д.В. Мастеров, С.А. Павлов, А.Е. Парафин, П.А. Юнин. Письма в ЖТФ 42, 82 (2016).

[9] Ю.Н. Дроздов, Д.В. Мастеров, С.А. Павлов, А.Е. Парафин, П.А. Юнин. ЖТФ 85, 109 (2015).

[10] D.V. Masterov, A.E Parafin, L.S. Revin, A.V. Chiginev, E.V. Skorokhodov, P.A. Yunin, A.L. Pankratov. SUST 30, 025007 (2017). 